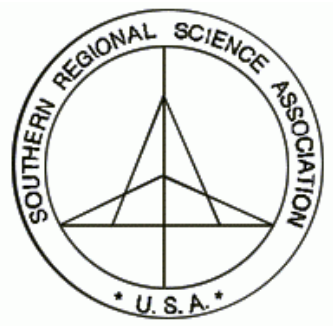

The Review of Regional Studies

Oklahoma State University

\title{
A Dynamic Estimation of Total Energy Demand for the Southern States*
}

\author{
Williams O. Olatubi \\ Center for Energy Studies, Energy, Coast, and Environment Building Louisiana State University \\ Baton Rouge, LA 70803, e-mail:wolatub@lsu.edu
}

Yan Zhang

Center for Energy Studies, Energy, Coast, and Environment Building, Louisiana State University Baton Rouge,LA 70803,e-mail: Zhang2@lsu.edu

\begin{abstract}
Few studies have examined in-depth the dynamics of energy consumption within regions or states in spite of the known differences in consumption patterns within nations. To adequately plan and forecast future energy needs and formulate conservation policies, states or regions need basic information such as income and price elasticities, consumption patterns, etc. Here we estimate the energy demand needs of the 16 states that belong to the Southern States Energy Board (SSEB) as a first step toward assessing future demand. A dynamic panel data framework is used to examine the long-run adjustment patterns. The preferred model shows a process of dematerialization over time. Per capita energy demand over time for the south is found to be relatively inelastic with respect to all the variables and more so for price $(-0.32)$ than income $(0.40)$. The level of income at which per capita energy consumption is maximized is $\$ 31,623$ (in 1995 dollars). Six of the 16 states in the SSEB are found to have reached or surpassed this level of income.
\end{abstract}

\footnotetext{
${ }^{*}$ An earlier version of this paper was presented at the $41^{\text {st }}$ Annual Southern Regional Science Association Meeting, Arlington, VA, April 2002. The authors wish to thank David Dismukes for reading and making helpful comments on an earlier draft and Ms. Versa Stickle for editorial assistance. Useful comments from two anonymous referees are appreciated.
} 


\section{INTRODUCTION}

This study was motivated by the renewed interest in the socio-economic impact of energy in nation-states and within regions in a nation, as vividly conveyed in the recent California energy debacle (Dismukes, Olatubi, and Mesyanzhinov 2002). Although this interest is not new, the quotations below exemplify a familiar refrain all over the world, especially in the industrialized nations, since the energy crisis of the mid-1970s.

A fundamental imbalance between supply and demand defines our nation's energy crises. .. . This imbalance, if allowed to continue, will inevitably undermine our economy, our standard of living, and our national security (National Energy Policy Development Group 2001).

Energy is the essential component determining the success of the interrelated economic, social and environmental aims of sustainable human development. . . . America faces a major challenge during the next 20 years to implement a national energy strategy that simultaneously meets the nation's energy needs, protects the environment, enables economic growth, ensures our national security and preserves the quality of life for all the nation.... Due to the California energy crisis, U.S. citizens are recognizing the significance of a stable, reliable, and secure energy supply. . . . Policy makers in the south should take this opportunity to focus on energy policy in our region and pursue actions that will sustain energy stability in the future (Southern States Energy Board 2001).

Several studies (e.g., Rothman, Hong, and Mount 1994; Al-Mutairi and Eltony 1996; Galli 1998; Medlock and Soligo 2001; and Gately and Huntington 2001) have examined the relationship between energy consumption and economic growth or development. It is well accepted that energy consumption is directly related to economic activities and that there are observable patterns in this relationship for a nation or groups of nations. These patterns include: (i) energy consumption is primarily driven by income and prices, although income is often more emphasized; (ii) there is a process of dematerialization ${ }^{1}$ over time; and (iii) the elasticity of income of energy demand is higher in developing than in developed countries.

The observable patterns noted above are mostly the result of studies of national and crossnational energy demand (e.g., Brookes 1973; Galli 1998; Kesavanathan, Swift, and Ruth 1998; and Sun 2003). Few studies (e.g., Lin, Bostsas, and Monroe 1985; Arsenault et al. 1995; Ryan, Wang, and Plourde 1996; and Garcia-Cerrutti 2000) have been undertaken to investigate the subnational or regional dimensions of energy demand. Among the exceptions are studies that focused on particular forms of energy such as petroleum, natural gas, and electricity, for example, Halvorsen (1976), Baltagi and Griffin (1983), Brown (1983), and Chen and Lee (1997). Some other research has focused on specific sectors of the economy - residential/household, manufacturing, utility, or transportation (e.g., Moody 1996; Silk and Joutz 1997; Kouris 1983; and Jones 1996). Within the U.S., there are no published studies of the aggregate energy demand of southern states and few relating to aspects of energy in individual states (e.g., Murray et al. 1978; Liu 1983). Country-level studies are important for understanding trends in global energy

1 The reduction in the ratio of resource use to economic output as output increases over time. 
needs and for assessing the concomitant implications for global growth and the environment. However, subnational regions often possess economic structures and endowments that differ from the national outlook. Such differences may impact regional patterns of energy demand and hence their economic growth paths. It is thus imperative to study the energy demand of regions to formulate appropriate policy responses that may be unique to such regions. Estimating elasticities and developing forecasts allow for realistic and achievable energy security and environmental policies that are consistent with national energy policy goals.

A major reason for the lack of regional studies of energy demand is the paucity of relevant regional data. Long-run estimation of energy demand requires time series of sufficient duration, which are often unavailable for states or subnational entities. A common approach that circumvents this problem is to use panel data. The panel data approach is not without its own statistical challenges, including issues of poolability and endogeneity. The southern states present a unique opportunity to study regional energy demand structures in a panel data setting for two main reasons. First, these states are a distinct contiguous political and economic entity in several respects. All these states are within the "Southern Regions" as defined by the U.S. Census Bureau, and all belong to the Southern States Energy Board (SSEB) ${ }^{2}-$ a sort of policy coordination organization. The assumption of poolability will thus appear plausible. Second, in spite of this unique "commonality," there are obvious differences that may also be important to understanding and accurately assessing future energy needs. The panel approach can accommodate these issues within empirically testable propositions.

In this study we use panel data of energy demands of the 16 states covering the period 1977 to 1999. The overall objective is to formulate an adequate model of the region's energy demand and use the model to assess relevant long-run energy demand elasticities. The remaining sections of the paper are organized as follows: section 2 briefly examines factors determining energy demand; section 3 describes the data used and their sources; section 4 examines trends in energy demand in the southern states; section 5 discusses the empirical model; section 6 presents the estimation procedures and results; and section 7 provides concluding remarks.

\section{FACTORS DETERMINING ENERGY DEMAND}

The conventional approaches to aggregate energy demand analyses have always premised consumption on two prime factors - price and income. Nonetheless, several previous studies, especially of a cross-national nature, have confined their analyses to income alone due to lack of consistent price data (e.g., Schmalensee, Stoker, and Judson 1998; Holtz-Eakin and Selden 1995). Other critical factors are also consistent with the economics of energy demand, such as structure of production, climatic differences, natural endowment, and technology. A fully specified energy demand model formulated to forecast future energy needs and its concurrent implications for economic growth and the environment should include most if not all of these factors. Unfortunately, the relevant data to construct these important variables are often lacking, especially in regional or subnational studies. This study includes, in addition to price and income variables, a proxy for the structure of production and climatic conditions in the states.

\footnotetext{
${ }^{2}$ These states include Alabama (AL), Arkansas (AR), Delaware (DE), Florida (FL), Georgia (GA), Kentucky (KY), Louisiana (LA), Maryland (MD), Mississippi (MS), North Carolina (NC), Oklahoma (OK), South Carolina (SC), Tennessee (TN), Texas (TX), Virginia (VA), and West Virginia (WV).
} 
Apart from its consistency with the economic theory of demand, the importance of price is evident in practical terms. The global economic effects of the 1973 oil price hike have ensured that no complete analysis of energy demand will ignore price effects. Energy price changes are not only important in terms of their direct impact on demand levels, but may also be an important policy variable that may be altered to influence how energy is used. In addition, relative price movements have implications for substitution within energy types and among an economy's total consumption bundle.

The income-energy consumption demand nexus has been the most examined, especially in the growth and development literature. The skewed focus on income as a determining factor of energy demand is partly a result of the relative ease with which relevant data can be assembled. Most studies of energy demand proxy national income by GDP or GNP data. These types of data are now readily available in most countries, whether developing or developed. The focus on income fits perfectly into economic development paradigms. One such paradigm is the assertion that development involves a process of dematerialization. In this dematerialization framework, it is observed that "across countries, the ratio of energy consumption to income (energy intensity) does not appear to be constant. .. . [E]nergy intensity tends to increase with income, as income rises from low levels, and then falls with income, as income increases beyond a critical level" (Galli 1998). This phenomenon is encompassed in the now familiar inverted " $U$ " curve between per capita energy use and per capita income over the economic development path. Furthermore, the income-energy demand relationship lends itself to more in-depth examination within the context of the well-established Engel curve analyses.

An often-neglected aspect of energy demand analysis is the influence of the structure of the economy. An economy dominated by agriculture is not likely to have the same levels of energy demand as one dominated by industry or even by services. In fact, for a given economy, structural changes occur as development progresses. Among industrializing economies, the type of industry also influences these changes. For example, an economy largely consisting of heavy manufacturing, such as iron and steel, petrochemicals, and motor vehicles, that relies on heavy energy input will have far more energy demand requirements per unit of output than another economy dominated by light manufacturing. At higher levels of development, countries move away from heavy manufacturing to services, where energy use is relatively minimal. Ignoring the potential influence of existing economic structure and its evolution over time may bias any estimate and forecast of future energy demand.

Table 1 depicts the structure of the manufacturing ${ }^{3}$ sector in the south over the past three decades. The shares of manufacturing in the region's output have clearly declined over the period, which is consistent with maturing economies. Although the shares of manufacturing have declined as income grows, the region's manufacturing shares are still slightly higher than the U.S. average. There are some differences in these trends among the states. States such as Florida, Louisiana, Maryland, Oklahoma, and Virginia tend to have a relatively lower share of manufacturing in total output (GSP). Furthermore, energy-producing states such as Texas, Louisiana, Okalahoma, Kentucky, and West Virginia appear to have a lower share of GSP in manufacturing than nonproducers. This table also shows that the trends in service sector shares

\footnotetext{
3 The manufacturing sector accounts for more than two-thirds of industrial energy consumption in the U.S.
} 
over time are in the opposite direction from manufacturing trends. For example, the share of services in state output has been on the increase over this period, and those states with declining shares in manufacturing appear to dominate this pattern. One general implication of these trends is to expect that as these economies expand and per capita incomes increase, there is likely to be continued structural change in manufacturing that should influence future energy consumption patterns.

Technological progress, or lack of it, may also influence the levels and patterns of energy demand. Technology exerts its influence on energy demand levels mostly via the improvement in the efficiency of energy and material use. A prime example of the importance of technologydriven energy efficiency is Japan. The dramatic decrease in Japan's energy intensity was brought about by improvement in conservation technologies and expanded substitution possibilities induced by innovation, which enabled smoother and less costly shifts between energy types (Taylor, Brown, and Boyle 1990).

Climatic factors have only been considered seriously in studies of household energy consumption. The apparent exclusion of climatic factors in national and international studies of energy demand is due to lack of relevant reliable data. It is obvious that living in a hot, cold, or mild climatic region will influence the levels and patterns of energy demand. Thus when relevant data are available, including climate variables will reduce potential bias in the estimated model of energy demand.

\section{TABLE 1}

Trends in Manufacturing and Service Industry Shares in Total Output (GSP) in Southern Economies

\begin{tabular}{|c|c|c|c|c|c|c|c|c|c|c|}
\hline \multirow[b]{2}{*}{ State } & \multicolumn{5}{|c|}{ Manufacturing Sector } & \multicolumn{5}{|c|}{ Service Sector } \\
\hline & 1977 & 1982 & 1987 & 1992 & 1999 & 1977 & $198 \overline{2}$ & 1987 & 1992 & 1999 \\
\hline $\mathrm{AL}$ & 25.10 & 23.30 & 24.60 & 22.50 & 19.00 & 10.00 & 11.50 & 13.40 & 15.90 & 16.90 \\
\hline $\mathrm{AR}$ & 25.70 & 24.30 & 25.10 & 24.00 & 22.50 & 10.20 & 11.50 & 12.90 & 14.80 & 15.60 \\
\hline $\mathrm{DE}$ & 35.40 & 33.80 & 27.30 & 19.30 & 14.20 & 10.50 & 11.70 & 12.00 & 13.60 & 15.50 \\
\hline FL & 10.60 & 11.00 & 10.30 & 8.90 & 7.20 & 16.10 & 17.40 & 19.30 & 22.40 & 24.40 \\
\hline GA & 23.50 & 21.30 & 20.60 & 18.50 & 17.00 & 11.30 & 12.50 & 13.90 & 17.30 & 19.20 \\
\hline KY & 30.00 & 25.00 & 26.40 & 26.00 & 27.50 & 9.10 & 10.80 & 12.70 & 14.60 & 16.00 \\
\hline LA & 16.40 & 11.30 & 15.40 & 17.00 & 15.20 & 9.50 & 9.90 & 13.30 & 16.60 & 17.60 \\
\hline MD & 15.60 & 13.30 & 10.40 & 8.70 & 8.10 & 14.60 & 17.30 & 19.20 & 22.40 & 24.20 \\
\hline MS & 24.70 & 22.30 & 24.40 & 25.60 & 20.60 & 9.80 & 10.50 & 10.90 & 13.20 & 17.40 \\
\hline $\mathrm{NC}$ & 33.50 & 31.10 & 30.60 & 29.30 & 24.10 & 9.80 & 10.80 & 11.80 & 14.30 & 16.40 \\
\hline $\mathrm{OK}$ & 14.90 & 13.00 & 15.90 & 18.30 & 16.90 & 11.00 & 10.60 & 14.40 & 15.90 & 18.20 \\
\hline $\mathrm{SC}$ & 30.90 & 28.30 & 27.00 & 26.70 & 21.40 & 9.70 & 10.80 & 11.70 & 14.10 & 16.40 \\
\hline $\mathrm{TN}$ & 28.50 & 25.80 & 24.70 & 24.50 & 20.80 & 11.60 & 14.10 & 15.60 & 18.90 & 20.60 \\
\hline $\mathrm{TX}$ & 18.10 & 15.20 & 15.10 & 13.90 & 14.00 & 11.00 & 11.60 & 15.50 & 18.20 & 19.90 \\
\hline VA & 20.10 & 18.40 & 16.70 & 15.50 & 13.10 & 11.70 & 13.80 & 15.90 & 18.60 & 22.60 \\
\hline WV & 21.20 & 15.70 & 17.10 & 15.80 & 16.00 & 9.00 & 11.10 & 13.20 & 15.90 & 17.90 \\
\hline South & 23.39 & 20.82 & 20.73 & 19.66 & 17.35 & 10.93 & 12.24 & 14.11 & 16.67 & 18.68 \\
\hline U.S. & 23.30 & 20.20 & 19.00 & 17.40 & 16.10 & 12.90 & 14.80 & 16.90 & 19.60 & 21.30 \\
\hline Energy & 20.95 & 17.25 & 19.08 & 18.92 & 18.10 & 11.11 & 12.59 & 14.52 & 17.19 & 19.18 \\
\hline Nonproducers & 24.85 & 22.96 & 21.71 & 20.10 & 16.90 & 10.92 & 12.11 & 13.93 & 16.43 & 18.55 \\
\hline Energy Intensive & 7.85 & 6.15 & 6.50 & 5.90 & 5.95 & & & & & \\
\hline
\end{tabular}


These factors do not in any way exhaust all possible key variables that may influence energy demand. Other factors such as the political and socio-environment may also influence the levels and types of energy used. Any future projections of energy demand and intensity should recognize the potential roles of all of these factors; unfortunately, many influential factors are not measured in a consistent manner that makes them usable in empirical work.

\section{DATA AND SOURCES}

This study does not intend to impose, a priori, a limited number of variables as the only determinants of energy demand. Thus in our analysis we used as many variables as there were relevant data in our estimation. The data coverage includes energy consumption, energy price, heating and cooling degree-days, index of proportion of manufacturing in state total output, and population for each of the 16 southern state members of SSEB for the period 1977 to $1999 .{ }^{4}$ These data are obtained from disparate published sources, including the Energy Information Administration (EIA), Bureau of Economic Analysis (BEA), Bureau of Labor Statistics (BLS), National Oceanic and Atmospheric Administration (NOAA), and Bureau of the Census (BOS). The data are subjected to the necessary transformation that is consistent with economic and econometric practice before use. A brief detail on each series is provided in an Appendix.

\section{SOUTHERN ENERGY DEMAND TRENDS}

The average per capita energy consumption in the south as a whole has been on an upward trend in the past two decades, except for the early- to mid-1980s. As shown in Fig. 1A, per capita average energy consumption in 1999 was above the peak of per capita BTU in 1980. It is obvious from this graph that if the trend prior to 1980 had continued, per capita consumption would have been at higher levels than what was actually observed and depicted. On the other hand, the average energy intensity has been on a downward trend since the late 1970s (Fig. 1B). Although intensity has trended downward, there appears to have been a slight adjustment in its path. The rate of decline in intensity in the early- to mid-1980s as seen in the slope of the curve is higher than subsequent periods. What accounts for these changes in consumption and intensity in the 1980s? A possible clue to the change in trends that occurred in the 1980s can be seen in real energy price trends, which probably induce structural change in consumption (Fig. 1D). Thus the rate of consumption slows with price increases and increases as price declines.

There appears to be two distinct price regimes in play: a period ending at about 1987, when energy prices were relatively high, and subsequent periods when real energy price declined. Real energy prices rose sharply in the early- to mid-1980s; hence demand fell sharply. The energy price increases are likely due to rising crude oil prices, precipitated in large measure by the Iran-Iraq war and the ensuing economic recession. While energy intensity is declining, real per capita output/income, ${ }^{5}$ as measured by GSP, follows a similar path in the opposite direction. Even during the period of sharp decline in energy consumption, real per capita income continued to grow, although a noticeable slight dip in the curve can be observed around 1983.

\footnotetext{
4 Data on Gross State Product (GSP) is only available from 1977 onward.

${ }^{5}$ Per capita output and per capita income will be used interchangeably in the remainder of this paper.
} 

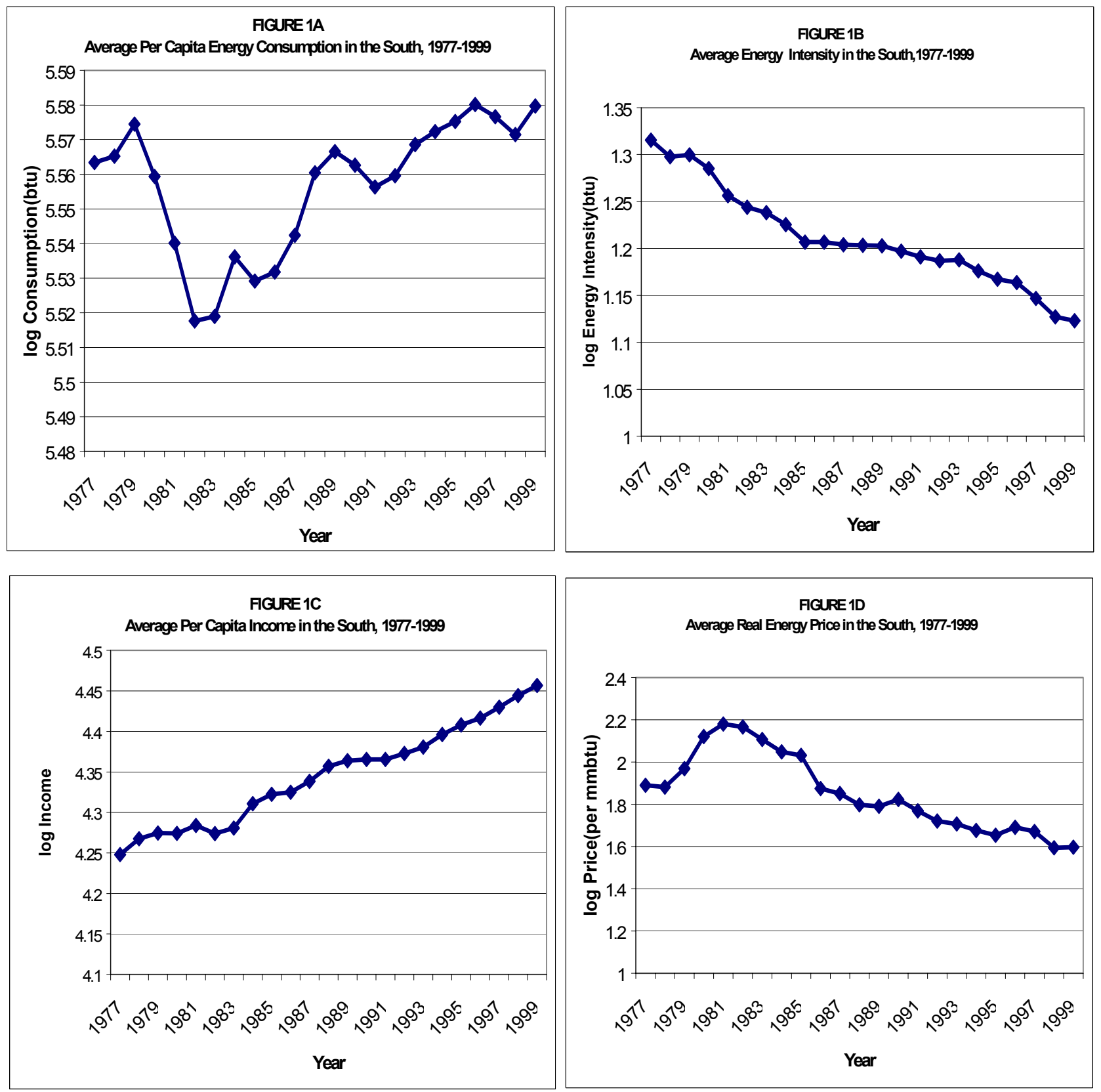

Table 2 shows the annual average growth in energy consumption, income, and energy intensity by state. Average per capita annual energy growth over this period for the south was positive $(0.24$ percent $)$. However, about half of the states in the region experienced negative growth in energy consumption. Mississippi had the highest annualized growth in energy (1.29 percent), while West Virginia had the slowest growth (-0.44 percent). 
TABLE 2

Annual Average Growth in Per Capita Income, Per Capita Energy, and Energy Intensity, 1977-1999

\begin{tabular}{crrr}
\hline State & $\begin{array}{c}\text { Average Per } \\
\text { Capita Energy } \\
\text { Growth (\%) }\end{array}$ & $\begin{array}{c}\text { Average Per } \\
\text { Capita Income } \\
\text { Growth (\%) }\end{array}$ & $\begin{array}{c}\text { Average Growth in } \\
\text { Energy Intensity (\%) }\end{array}$ \\
\hline AL & 0.330 & 2.230 & -1.850 \\
AR & 0.800 & 2.240 & -1.380 \\
DE & -0.120 & 3.150 & -3.130 \\
FL & 0.090 & 2.410 & -2.250 \\
GA & 0.630 & 3.060 & -2.330 \\
KY & 0.690 & 2.030 & -1.300 \\
LA & -0.200 & 1.330 & -1.180 \\
MD & -0.040 & 2.480 & -2.440 \\
MS & 1.290 & 1.990 & -0.670 \\
NC & 0.500 & 2.930 & -2.330 \\
OK & -0.120 & 1.390 & -1.340 \\
SC & 0.610 & 2.590 & -1.900 \\
TN & -0.320 & 2.630 & -2.850 \\
TX & -0.330 & 1.860 & -2.070 \\
VA & 0.500 & 2.690 & -2.120 \\
WV & -0.440 & 1.090 & -1.520 \\
\hline South Avg. & 0.240 & 2.260 & -1.910 \\
\hline
\end{tabular}

Average annual per capita income growth in the region was about 2.26 percent between 1977 and 1999. Unlike energy growth, all southern states show positive per capita income growth rates, with the highest rates in Delaware (3.15 percent) and the lowest in West Virginia (1.09 percent). Consistent with earlier observation of declining energy use per output, the average annual energy intensity was negative for the south as a whole (-1.91 percent). In the case of average intensity of energy use over the period, Mississippi led ( -0.67 percent), while Delaware appears to be the most energy efficient $(-3.13$ percent). It seems there are no distinct and clear patterns to these observations; however, many energy-producing states ${ }^{6}$ have negative energy growth, below-average per capita income growth, and below-average energy use efficiency.

Table 3 presents the trend in growth rates from 1977 to 1999. In 1999, southern states' per capita energy consumption rose by 3.32 percent from its 1977 values, per capita income rose by 62.9 percent, and energy intensity fell by 34.42 percent on the average. As a way to discern the growth path in the efficiency of energy use, we broke the period in two: 1977-1987, when energy price levels were relatively high, and the next 12 years, when energy price levels were relatively low. As depicted in the last three columns of Table 3, on the average, the decline in intensity is likely the result of a combination of three factors - real energy efficiency improvement, structural changes, and fuel switching. Taken together, Figures 1A and 1D give an indication of the role or the importance of energy intensity in restraining energy consumption.

Since the relationship between income growth and energy demand generate the most interest in energy demand analyses, we have graphed these two key variables in Figures 2 and 3. In

\footnotetext{
${ }^{6}$ These are KY, LA, OK, TX, and WV. All these states are either net energy producers or meet at least 90 percent of the per capita energy consumption needs in 1999.
} 
TABLE 3

Growth in Per Capita Energy Consumption, Income, and Energy Intensity in the South, 1977-1999

\begin{tabular}{ccc|crc}
\hline & Energy Consumption & $\underline{\text { Income }}$ & \multicolumn{4}{c}{ Energy Intensity } \\
\cline { 5 - 6 } State & Growth & \% Growth & \% Growth & \% Growth & \% Growth \\
AL & $1977-1999$ & $1977-1999$ & $1977-1987$ & $1987-1999$ & $1977-1999$ \\
\hline AR & 6.29 & 61.46 & -24.47 & -12.85 & -34.17 \\
DE & 16.46 & 61.52 & -32.53 & 6.86 & -27.90 \\
FL & -6.22 & 96.42 & -35.68 & -25.77 & -52.26 \\
GA & 1.24 & 68.02 & -28.49 & -15.73 & -39.74 \\
KY & 14.19 & 92.79 & -23.56 & -22.51 & -40.77 \\
LA & 14.61 & 54.39 & -19.14 & -8.19 & -25.76 \\
MD & -7.78 & 29.22 & -17.12 & -13.89 & -28.63 \\
MS & -1.88 & 70.37 & -26.55 & -21.59 & -42.40 \\
NC & 30.80 & 53.43 & -10.70 & -4.54 & -14.75 \\
OK & 10.57 & 87.15 & -19.75 & -26.39 & -40.92 \\
SC & -4.00 & 32.78 & -13.06 & -16.84 & -27.70 \\
TN & 13.56 & 74.26 & -21.75 & -16.72 & -34.83 \\
TX & -7.39 & 75.67 & -31.40 & -23.16 & -47.28 \\
VA & -8.49 & 47.67 & -18.04 & -24.39 & -38.03 \\
WV & 11.02 & 78.50 & -22.99 & -19.24 & -37.81 \\
\hline Southern Avg. & -11.75 & 25.92 & -11.42 & -20.88 & -29.92 \\
\hline
\end{tabular}

these graphs, logarithm scales are used to enable us to compare growth rates consistently. To aid visual comparison, three parallel lines are drawn so that states with similar proportional growth rates for income and energy demand will lie parallel to these lines. States whose points lie on the $45^{\circ}$ lines exhibit equal growth rates in both variables.

In Figure 2A, we compare the paths of growth for major energy producers. These states show different patterns of growth in both periods. For these five states, per capita energy demand falls faster than income was rising during a period of relatively higher energy prices. Except for West Virginia, energy consumption and income rose simultaneously in the period of falling energy prices. For these energy producers, income grew at a slower pace than energy consumption in the first 10 years than in the following 12 years. In fact, 1987 to 1999 was a reversal of the pattern in the previous 10 years. Similar depictions of growth patterns are indicated for net energy consumers (or non-major producers) in Figure 2B. In this case, except for Arkansas, Alabama, Delaware, and Tennessee, there are no distinct patterns of growth between energy consumption and income in the periods of rising energy prices and energy price declines. For most of these net energy-consuming states, per capita income generally rose with income, especially in the period of falling energy prices.

Actual growth rates in energy and income within the period of our analysis are examined in Figure 3. Except Mississippi, all the states with less than 60 percent growth in per capita income are major energy producers. All these energy-producing states also show negative growth in per capita energy consumption, as do three of the net energy-consumers - Maryland, Tennessee, and Delaware. Most of the net consumers show both high-income growth and relatively higher energy consumption per capita. With the exception of Mississippi, all other southern states show growth rates less than 25 percent in per capita energy consumption. 

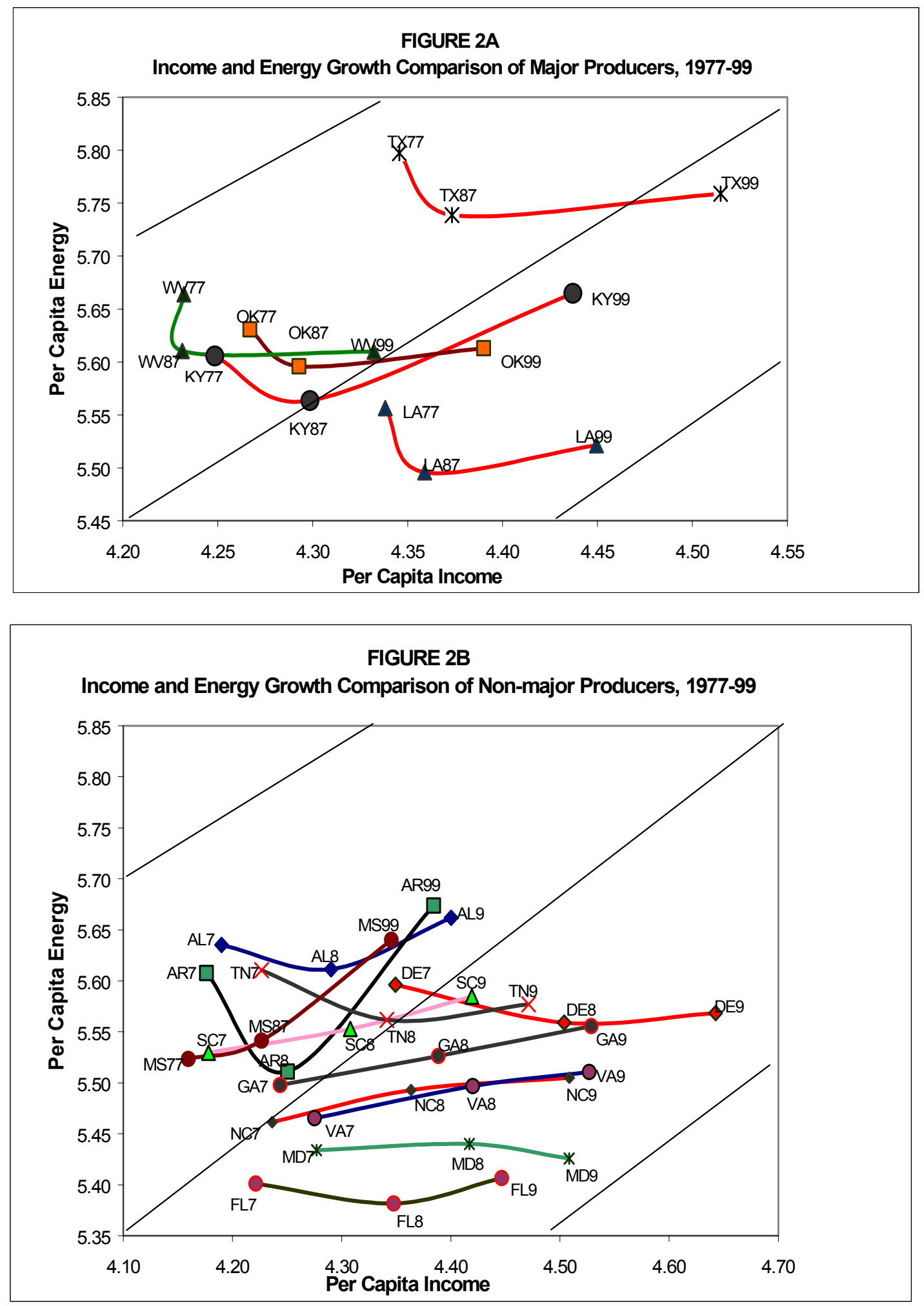


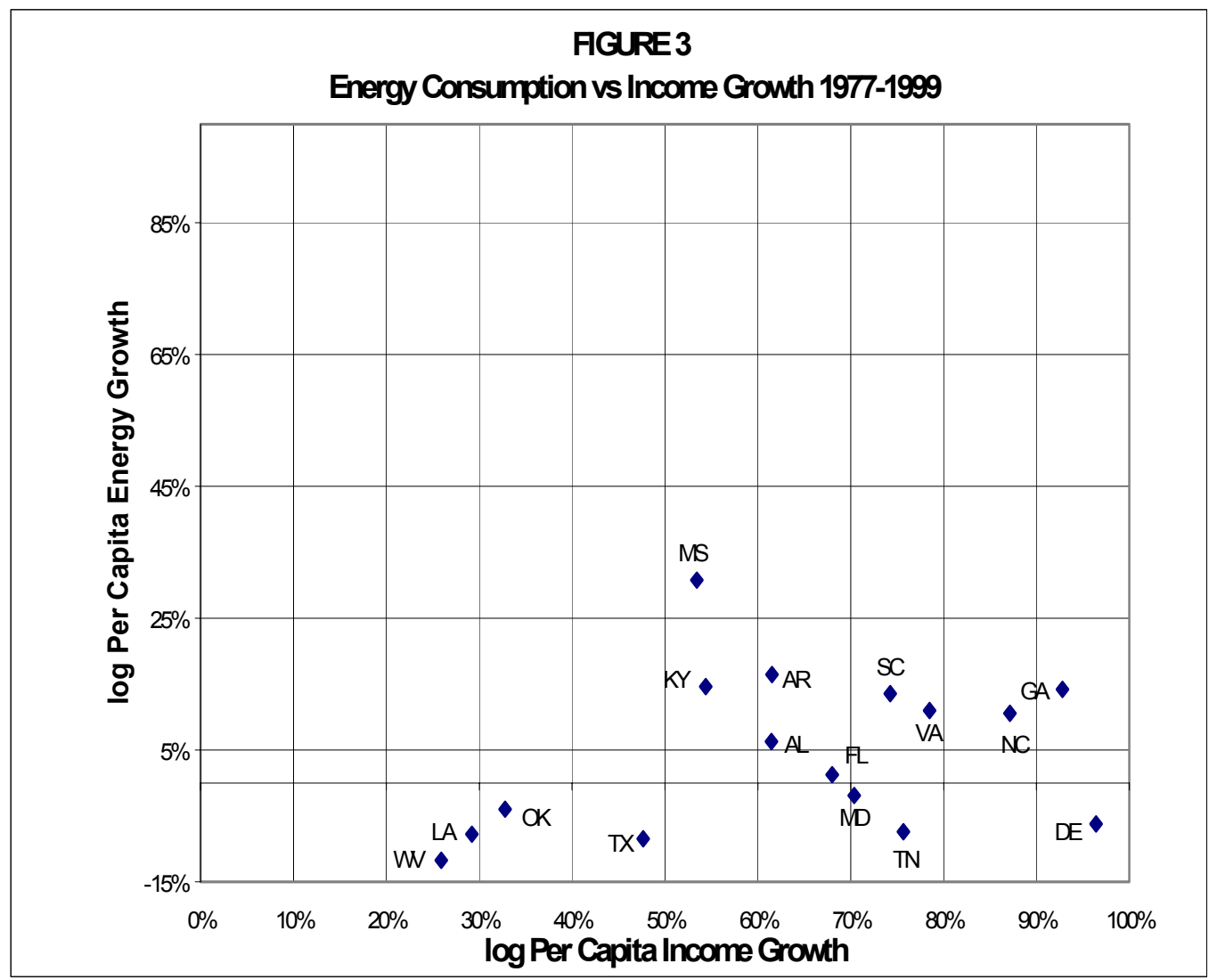

\section{EMPIRICAL MODEL}

Various specifications have been employed in studies of energy demand. The most common specifications have been limited to the price and income variables in a linear fashion, although some recent applications have argued for nonlinearity at least in the income variable (e.g, Galli 1998; Judson, Schmalensee, and Stoker 1999; Medlock and Soligo 2001). As noted earlier, most of the previous research is limited to national economies. Because regional or subnational economies' energy-demand relationships are less understood, the reduced form equation of energy demand formulated here is initially made as general as possible in order to avoid imposing a particular structure on the relationship. Such imposition has been known to impact elasticity estimates (Dahl 1991).

Our general panel data formulation of southern energy demand is of the form:

$$
\ln e_{i t}=\alpha_{0}+\alpha_{i}+\gamma_{t}+B^{\prime} X_{i t}+\varepsilon_{i t} .
$$

Equation 1 is the familiar two-way effect panel data model. ${ }^{7}$ Here subscript $i$ references states and $t$, time period; $e_{i t}$ (i.e., $E_{i t} / N_{i t}$ ) is the per capita energy consumption; $\alpha_{0}$ is the overall regres-

\footnotetext{
7 The obvious problem of multicollinearity in (1) is removed by imposing the following conditions: $\Sigma_{i} \alpha_{i}=\Sigma_{t} \gamma_{t}=0$.
} 
sion constant; $\alpha_{i}$ is the individual group (state in this case) effects; $\gamma_{t}$ represents the time effects for each period. The fixed effects take particular account of the possible heterogeneity among southern states. Fixed effects capture differences arising from such issues as natural resource endowments, mix of output, tax and subsidy regimes, and regulatory frameworks that persist over time. The time effects are meant to reflect changes in policies, in the political and socioenvironment, and in technology. The $B$ and $X_{i t}$ are vectors of coefficients and of independent variables, respectively. The vector $X$ includes log of real energy price $\left(P_{i t}\right)$; real per capita income, $y_{i t} ; S_{i t}$, which denotes index of manufacturing proportion in total output; and $W_{i t}$ indicating weather variable $H$, or $C$ (defined in the Appendix). The vector $X$ also includes a oneperiod lag of $e_{i t}$ (i.e, $e_{i t-1}$ ), which introduces an element of dynamics in energy consumption and allows for the inclusion of an adjustment path in the long-run demand. The error time, $\varepsilon_{i t}$, is assumed to have the usual properties.

Until recently, studies of aggregate energy demand have formulated (1) as linear in price and income. Recent studies of Galli (1998); Schmalensee, Stoker, and Judson (1998); and Medlock and Soligo (2001) included income as a nonlinear determinant of per capita energy demand. These recent studies, while assuming linear prices, however, do not foreclose the possibility of nonlinearity in prices. ${ }^{8}$ Thus, the price and income variables in $X$ have the specific nonlinear form specified as:

$$
\begin{aligned}
& P_{i t} \equiv F_{1}\left[P_{i t}\right] \equiv P_{i t}^{\beta_{1}+\beta_{2} \ln P_{i t}} \\
& y_{i t} \equiv F_{2}\left[y_{i t}\right] \equiv y_{i t}^{\beta_{3}+\beta_{4} \ln y_{i t}} .
\end{aligned}
$$

The preceding functional forms assume nonlinearity in prices and income. In particular, we assume a quadratic approximation to the underlying true but unknown function. The quadratic functional form assumed for price here is simplistic and quite restrictive, but it is meant to at least demonstrate potential problems in current applications. The estimated form of equation (1) in our initial generalized model is

(2) $\ln e_{i t}=\alpha_{0}+\alpha_{i}+\gamma_{t}+\ln F_{1}\left[P_{i t}\right]+\ln F_{2}\left[y_{i t}\right]+\beta_{5} \ln w_{i t}+\beta_{6} \ln S_{i t}+(1-\delta) \ln e_{i t-1}+\varepsilon_{i t}$ where $\delta$ is the adjustment coefficient such that it takes values of 0 to 1 . If $\delta$ is 0 , then the adjustment to long-run equilibrium is infinitely long; and when $\delta$ is 1 , then the adjustment path is instantaneous. The desired long-run level of energy consumption, $\ln e_{i t}^{*}$, is then

(3) $\ln e_{i t}^{*}=\alpha_{0}+\alpha_{i}+\gamma_{t}+\varphi_{1} \ln P_{i t}+\varphi_{2}\left(\ln P_{i t}\right)^{2}+\varphi_{3} \ln y_{i t}+\varphi_{4}\left(\ln y_{i t}\right)^{2}+\varphi_{5} \ln w_{i t}+\varphi_{6} \ln S_{i t}$

and the corresponding desired long-run energy intensity is

\footnotetext{
${ }^{8}$ Non-linearity of (1) in prices is a particularly tenable proposition in southern energy demand studies because of potential impact of regulatory regimes in play in electricity production and consumption in the states during this period. Given the myriad of energy markets, to select a particular functional form that best captures the energy markets will be quite a challenge. Any functional form assumed, especially a quadratic form such as assumed here, will likely influence the results obtained in some way (Berck and Roberts 1996).
} 


$$
\begin{aligned}
\left(\ln e_{i t}^{*}-\ln y_{i t}\right)= & \alpha_{0}+\alpha_{i}+\gamma_{t}+\varphi_{1} \ln P_{i t}+\varphi_{2}\left(\ln P_{i t}\right)^{2}+\left(\varphi_{3}-1\right) \ln y_{i t}+\varphi_{4}\left(\ln y_{i t}\right)^{2} \\
& +\varphi_{5} \ln w_{i t} \varphi_{6} \ln S_{i t} .
\end{aligned}
$$

The long-run elasticities of energy demand are the following.

Price: $\quad \varphi_{1}+2 \varphi_{2} \ln P_{i t}$

Income: $\varphi_{3}+2 \varphi_{4} \ln y_{i t}$

Weather: $\varphi_{5}$

Structure: $\varphi_{6}$.

The long-run elasticities of energy intensity with respect to price and weather are the same, whereas it is $\left(\varphi_{3}-1\right)+2 \varphi_{4} \ln t_{i t}$ for income. It is expected that $\left(\varphi_{1}+2 \varphi_{2} \ln P_{i t}\right)<0$ and $\left(\varphi_{3}+\right.$ $\left.2 \varphi_{4} \ln y_{i t}\right)>0$; that is, demand should decline with price increases and increase as income rises. If the proposition of dematerialization is valid, then initially in the development process, energy demand should rise with income (i.e., $\varphi_{3}>0$ ) and then fall in the later stages of development (i.e., $\varphi_{4}<0$ ). In the south, the coefficient $\varphi_{5}$ should be positive for cooling degree-days, $C$. The relevant coefficients in (3) and (4) can be recovered from the maintained hypothesized relationship in (2). These elasticity parameters are recoverable from (2) using the following relationship: $\varphi_{k}=\beta_{k} / \delta$ for $k=1,2,3 \ldots 6$. These forms of income and price elasticities imply nonconstant elasticities. For income, in particular, it also implies that there is a level of per capita income that maximizes energy consumption or intensity. This maximum point occurs where $\left(\varphi_{3}\right.$ $\left.+2 \varphi_{4} \ln y_{i t}\right)=0$. Medlock and Soligo (2001) refer to this point as "zero-point" and note that the shape of the underlying curve is not necessarily symmetric in prices and income.

\section{ESTIMATION PROCEDURES AND RESULTS}

In the estimation of equation (2) we assume a reduced form of the underlying structural form. Hence prices, income, weather, and structure of production are assumed at least to be weakly exogenous to energy consumption. However, the presence of the lagged dependent variable complicates the estimation of (2) using OLS. Because the error term in (2) is inherently correlated with the lagged endogenous consumption term, the OLS estimator is not unbiased and inconsistent, even in large samples (Nickell 1981; Ridder and Wansbeek 1990; Kiviet 1995). Alternative approaches to estimating (2) to remove the consequences of endogeneity have been proposed (see, for example, Anderson and Hsiao 1981; Arellano 1989; Arellano and Bond 1991). Recent advancements in time series econometrics offer much more ambitious and complex estimators. ${ }^{9}$ In spite of these developments in the literature, the most common approach to dealing with the problem is by the use of instrumental variables (IV). Thus it is usual to use two-stage least squares (2SLS) to consistently estimate (2), which we also employ.

In the first stage of the 2SLS approach, we regressed all the exogenous variables in (2) in their lags and levels on $\ln e_{i t}$. The predicted values of the endogenous variable from the first stage-regression $\ln \hat{e}_{i t}$ are used as the instrument for the lagged endogenous variable $\ln e_{i t-1}$ in the

${ }^{9}$ See a recent comprehensive survey of Baltagi and Kao (2000). 
second stage regression. In this second stage, all other exogenous variables serve as their own IV.

Since there is no theoretical basis for imposing a particular structure on regional energy demand, we estimate (2) as a maintained hypothesized model and evaluate its performance based on theory and other statistical diagnostic tools. Based on this initial run, other possible models that are regarded as "nested" in (2) are also evaluated. Overall, five other models are evaluated in this manner. The results presented in Table 4 consist of only the final three plausible models based on these initial evaluations. ${ }^{10}$ Figures in parenthesis are standard errors.

Given that the initial runs show that the quadratic term in price may be the problem source and the temperature variable is consistently insignificant, we estimate equation (1) without these two terms. This is the Model 1 reported in Table 4. All the coefficients in Model 1 show the correct signs and are highly significant except for $S$, which is only significant at the 10 percent level.

Statistical diagnosis of Model 1 shows that it is robust in the parameter estimates and consistent with economic theory. ${ }^{11}$ In particular, the estimates in Model 1 indicate a process of dematerialization in southern energy demand structure. As stated earlier, recent studies suggest that at initial stages of economic development, energy intensity should rise with income and then fall as a threshold per capita income level is reached. This is the logic of the inverted " $U$ " shape implied by the income terms coefficient in Model 1. Identification of this "turning-point" could aid in identifying the relative position of a country or a region in the development path or the role of energy in moving along that path.

Since one of the major objectives of this paper is to formulate an adequate energy demand model for the south, we estimated two additional models that are often imposed, a priori, in the literature. In Model 2, we estimate Model 1 without the square income term and ignoring time effects. Recent studies of energy demand such as Gately and Huntington (2001) have estimated such a model for OECD and developing countries. This model is estimated without the time effects but accounting for possible autocorrelation. The results as shown indicate an equally possible model of southern energy demand given the significance and signs of all the variables. Model 3 only differs from Model 2 with respect to the inclusion of possible time effects. The results of Model 3 indicate an equally plausible model of energy demand for the south with time effects being significant.

\footnotetext{
${ }^{10}$ The first three models considered appear to be implausible because they either show temperature, the price, and/or the economic structure variables insignificant or carrying the wrong sign(s). For example, the first estimation of (2) showed both coefficients on price are significant but wrongly signed, and both weather and economic structure are insignificant; the next run, which is a re-estimation of equation (2) without the most insignificant variable also produce price terms with the wrong signs and the economic structure variable still insignificant. Substituting economic structure for temperature and re-estimating does not produce an acceptable model either.

${ }^{11}$ These include tests for poolability of the entire panel, which was accepted by both the Lagrangian multiplier (LM) and log-likelihood ratio (LR) tests. We also tested Model 1 against the model with fixed effects only using LR test. Although it is not necessary given the nature of our sample, Hausman's test of all the models against the random effects specification is consistently rejected in all cases. There is also no significant autocorrelation problem detected in Model 1.
} 
Finally, because any of the Models 1-3 could have been a suitable model of southern energy demand from a theoretical perspective, we treat Models 2 and 3 as nested in Model 1. Likelihood ratio tests are then employed to select which of these is the most appropriate model. The LR tests consistently reject Models 2 and 3 in favor of Model 1. Therefore, Model 1 is deemed to be an adequate model of energy demand for the south for the period considered in this study.

\subsection{Long-Run Elasticities for the South}

The elasticities of energy demand with respect to $P, S$, and energy intensity are obtained from Model 1 using $\varphi_{k}=\beta_{k} / \delta$, as indicated previously. In Model 1 , however, income elasticity is a function of $y_{i t}$. The calculated elasticities for the region over time are shown in the bottom part of Table 4. Income elasticities are based on average per capita income for the south over time. These results imply a relatively inelastic demand for energy and energy intensity. In absolute terms, energy intensity is more responsive to income than per capita energy consumption. Even though the magnitude of the difference between price and income elasticities may not be large, these results show that energy demand responds more to income changes than to price. At higher incomes, more energy per capita is used, although at a declining rate. On the other hand, higher income widens choice opportunities; investments in new technologies and innovations are possible. For example, industries can afford more expensive but energy conserving techologies, which lead to more efficient energy use.

\section{TABLE 4}

Regression Estimates and Implied Elasticity

\begin{tabular}{|c|c|c|c|}
\hline Independent Variables & Model 1 & Model 2 & Model 3 \\
\hline Constant & $\begin{array}{l}-4.7806 \\
(1.8362)\end{array}$ & --— & --- \\
\hline Price $(\mathrm{P})$ & $\begin{array}{l}-0.1053 \\
(0.0491)\end{array}$ & $\begin{array}{l}-0.0772 \\
(0.0183)\end{array}$ & $\begin{array}{c}-0.0839 \\
(0.0173)\end{array}$ \\
\hline Income $(\mathrm{Y})$ & $\begin{array}{c}2.6310 \\
(0.8489)\end{array}$ & $\begin{array}{c}0.1017 \\
(0.0289)\end{array}$ & $\begin{array}{c}0.0800 \\
(0.0260)\end{array}$ \\
\hline Income-squared $\left(\mathrm{Y}^{2}\right)$ & $\begin{array}{l}-0.2878 \\
(0.0973)\end{array}$ & - & -_- \\
\hline Structure (S) & $\begin{array}{c}0.0182 \\
(0.0102)\end{array}$ & $\begin{array}{c}0.0442 \\
(0.0094)\end{array}$ & $\begin{array}{c}0.0403 \\
(0.0090)\end{array}$ \\
\hline Lagged-Consumption $\left(\mathrm{e}_{\mathrm{t}-1}\right)$ & $\begin{array}{c}0.6732 \\
(0.0464)\end{array}$ & $\begin{array}{c}0.6275 \\
(0.0350)\end{array}$ & $\begin{array}{c}0.6526 \\
(0.0335)\end{array}$ \\
\hline Adj. R-square & 0.9806 & 0.9748 & 0.9754 \\
\hline SSE & 0.0482 & 0.0640 & 0.0661 \\
\hline $\mathrm{AIC}$ & -5.8140 & -5.6080 & -5.6280 \\
\hline Log Likelihood & 1065.6600 & 962.2200 & 1010.6200 \\
\hline \multicolumn{4}{|l|}{ Long-Run Elasticity } \\
\hline Price & -0.32 & -0.21 & -0.24 \\
\hline Income & 0.40 & 0.44 & 0.29 \\
\hline Structure & 0.06 & 0.12 & 0.15 \\
\hline Intensity & -0.60 & -0.56 & -0.71 \\
\hline
\end{tabular}


According to our estimates, if the southern economy should grow at 2 percent $^{12}$ annually, energy demand will grow by 0.80 percent and energy intensity will decline by 1.2 percent. The coefficient of long-run adjustment indicates that if there is a shock to the system, say an unexpected price hike, about 33 percent of the adjustment to equilibrium level of energy demand will occur in one year. This level of adjustment implies it will take at most four years for demand to fully adjust to a change in price or income. ${ }^{13}$ Furthermore, the specification of Model 4 used implies that both income and price adjustment paths are the same. While the assumption of equal price and income adjustment may not be true in fact, the estimate gives some idea of the expected duration of potential instability in energy demand following an exogenous shock.

Table 5 reports the elasticity estimates for selected years. These elasticities are all positive for all the states except for Delaware in 1999. ${ }^{14}$ For the south, the average income elasticity of energy demand was 0.57 in 1977, falling by 28 percent to 0.41 in 1987 , and by 1999 it was 0.2 percent (a 65 percent decline from 1977). These trends are repeated in virtually all the states. This confirms the observation in the economic development literature that income elasticity declines (more inelastic) at higher per capita income. Thus high per capita income states such as Delaware and Virginia have a relatively more inelastic income elasticity of energy demand in 1999 than low-income states such as Mississippi and West Virginia.

\section{TABLE 5}

Income Elasticity of Energy Demand for Selected Years in the South

\begin{tabular}{cccc}
\hline States & 1977 & 1987 & 1999 \\
\hline AL & 0.67 & 0.49 & 0.30 \\
AR & 0.70 & 0.56 & 0.33 \\
DE & 0.39 & 0.12 & -0.13 \\
FL & 0.62 & 0.39 & 0.22 \\
GA & 0.58 & 0.32 & 0.07 \\
KY & 0.57 & 0.48 & 0.24 \\
LA & 0.41 & 0.37 & 0.21 \\
MD & 0.52 & 0.27 & 0.11 \\
MS & 0.72 & 0.61 & 0.40 \\
NC & 0.59 & 0.37 & 0.11 \\
OK & 0.54 & 0.49 & 0.32 \\
SC & 0.69 & 0.46 & 0.27 \\
TN & 0.61 & 0.40 & 0.18 \\
TX & 0.40 & 0.35 & 0.10 \\
VA & 0.52 & 0.27 & 0.08 \\
WV & 0.60 & 0.60 & 0.42 \\
\hline
\end{tabular}

\footnotetext{
${ }^{12}$ This figure is below the U.S. average for the past decade and is chosen to reflect the consistent underperformance of the southern economies relative to the national average.

${ }^{13}$ This value is within the range reviewed for gasoline studies in Espey (1996) and for total energy in Prosser (1985) and Dahl (1994).
} 


\subsection{Dematerialization}

The acceptance of Model 1 as the most appropriate model implies there is a particular level of per capita income at which energy demand or intensity is maximized. Such a "turning point" is consistent with the inverted "U" shape of Model 1. That is, using our estimated relationship in Model 1 and as stated earlier, we can estimate this level of income by solving the long-run elasticity relation $\left(\varphi_{3}+2 \varphi_{4} \ln y_{i t}\right)$ at its zero-point for the implied $y$. This per capita income "turningpoint" estimated for the south is $\$ 31,623$ (in 1996 dollars). These results indicate that the following states have reached this point and in the years indicated: Delaware (1987), Georgia (1998), Maryland (1999), North Carolina (1999), Texas (1998), and Virginia (1998).

\section{POLICY IMPLICATIONS}

What do these results mean for policy makers in the south in particular and the U.S. in general? What potential consequences are there for the U.S. environment? First, it is expected that the economies in the south will continue to expand and per capita income will continue to rise. As income continues to rise and given the results here that show positive income response to energy demand, total energy requirements in the region are bound to rise. This conclusion is reinforced by the fact that only six of the 16 states have peaked in their use of energy, i.e., most of the states are still "located" in the rising part of the inverted U curve. However, the increased income will not be matched by the increase in energy consumption as observed income elasticities are on the decline and inelastic in the long run for the region (Table 5). Although there are no major differences among the states with regard to expected per capita rise in energy consumption, six of the states - Delaware, Georgia, Maryland, North Carolina, Texas, and Virginia - had relatively low elasticities of income by 1999. It is expected, therefore, that these states will only increase their energy needs modestly in the future, ceteris paribus. It is also noted that in terms of income, energy producers are not necessarily different from nonproducers in the region.

Second, because most of these states have not reached the maximum per capita consumption predicted by the process of dematerialization, total energy requirements for the U.S. are likely to be higher than often predicted by previous studies. This observation is due to the fact that previous studies have shown that the U.S. and most of the developed world reached the maximum per capita energy demand in the 1970s or early 1980s. Since these studies used aggregated data for each country, subregions or states within these countries are implicitly assumed to be simultaneously "located" on the downward side of the inverted U curve. If the results here hold and given the current state of energy supply and demand, it is likely that U.S. imports of some forms of energy such as petroleum have been underestimated.

Third, increasing total energy requirements for the states and hence the U.S. has implications for the environment. It means we should expect more energy-related pollution, such as $\mathrm{CO}_{2}$ emissions, in the near future. The observed declines in income elasticity, however, imply that

\footnotetext{
${ }^{14}$ This negative income elasticity is not consistent with theory. Similar results have also been reported for highincome countries in Schmalensee, Stoker, and Judson (1998), Judson, Schmalensee, and Stoker (1997). However, this may be an artifact of measurement errors in the data given its high aggregation.
} 
the increases expected will likely be far lower than they would be otherwise. This presumes current policy, technology, and price regimes continue to hold.

Fourth, given that the elasticity of energy intensity (-0.6) is far above that of price, income, and economic structure, it is expected that growth in output will result in far less use of energy per output in the future, ceteris paribus. Coupled with the results in Table 1 that show a declining role for manufactures and an increasing share of service sectors in the region's economies, it is safe to predict a pattern of growth for the south that is in line with what the economic growth literature classifies as maturing economies.

The above analyses are predicated on the current situation - energy prices, technology, policies, and growth rates - staying the same. A change in relative energy prices will affect the level of energy use in general but may spur substitution from one form of energy to another. It is also possible that it will alter the product mix of industries. In addition, an increase/decrease in oil and gas prices, for example, may alter the pattern reported in Table 1 as industry shifts away from or to energy-intensive manufacturing, implying even less or more energy requirement in the future. As the development of "high-tech" industries in the 1990s shows, energy intensity may decline further even as output and productivity rise phenomenally. Whether the south will benefit from such developments in the economy may also depend on the pace of deregulation in the energy markets, especially the electricity sector. Given that the south's performance indicators are generally below the U.S. average (Table 1), careful deregulation programs in the region will enhance more competition and thus more optimal resource allocation that may enhance the spate of convergence to U.S. average indicators clearly evident in these trends. ${ }^{15}$ How each state responds will also depend on its particular situation; for example, a decrease in oil and gas prices may reduce income in producing states such as Louisiana, Texas, and Oklahoma (Brown and Yucel 1995), thus potentially reducing consumer demand for energy in these states. On the other hand, such a development may cause industries in those states to use more energy and postpone investments in energy-saving technologies, given current trends.

\section{CONCLUDING REMARKS}

Future economic growth in the south will be accompanied by higher energy consumption. Nonetheless, as the economy becomes more service oriented and there are continued innovations in industry, energy intensity is likely to decrease. Per capita energy consumption will also continue to rise as income grows but at declining rates. These are the imperatives suggested by growth theory. Understanding the nature and path of this process of energy consumption is important for planning and environmental well being in the south. This paper is a step toward understanding the energy demand in this region and toward developing an adequate model to assess relevant elasticities and forecast future energy needs.

Our results show that the appropriate form of southern energy demand fits the dematerialization process. This result also shows that imposing a particular structure on energy demand as is often done in similar studies is not appropriate. Such an imposed structure leads to different conclusions about the potential levels and rate of growth in future energy demand.

\footnotetext{
15 The deregulation debacle in California has slowed the pace of deregulation in most southern states, with some actually contemplating abandoning it altogether.
} 
Southern energy demand is inelastic to price and income. Also, the elasticities have declined over time. These elasticity estimates are reasonably within the range of what has been estimated for OECD countries. Energy intensities are also estimated to decline faster than per capita energy consumption is increasing as income grows. This implies that for some states the socalled "zero-point" or the level of per capita income, which maximizes per capita energy demand, has been reached. We estimate this income level has been reached in Delaware, Georgia, Maryland, North Carolina, Texas, and Virginia and conclude that these state economies are at the later stages of growth. Such high-growth economies are likely to mean declines in overall growth rates in energy consumption in the future for the region. Our results thus imply fairly optimistic news for future energy needs in the south and for the environment given current trends.

\section{APPENDIX}

- Energy Consumption (E): Aggregate energy consumption is measured in BTU. Consumption levels for each state are obtained from the U.S. Energy Information Administration (EIA). All energy sources are added in BTU to create end-use sector and total energy consumption estimates. Energy consumed by each sector - industrial, commercial, transportation, residential, and electric utility - is converted to BTU equivalent based on standard energy conversion factors for each source of energy used, i.e., coal, natural gas, petroleum, wood, waste, and electricity. Total energy consumed is calculated as the sum of all energy sources. Details of the underlying estimation and calculations of energy quantities can be obtained from: http://www.doe.gov/emeu/sedr/contents.html. The per capita energy consumed is then estimated by dividing the total energy consumed in each state by the resident population as published by the U.S. Bureau of the Census.

- Energy Prices (P): The price of energy consumed is measured in dollars per million BTU and is an average (consumption-weighted) over all sectors. This series is collected from the EIA. EIA estimates price for each sector by dividing energy expenditures into quantities consumed. To estimate end-use expenditures, estimated BTU quantities are multiplied by observed prices for each energy source-type, or imputed prices when direct measures are unavailable. Details of the underlying estimation and calculations of energy quantities can be obtained from: http://www.doe.gov/emeu/sedr/contents.html. The average "Total Energy" prices used are then converted to real levels by using the Consumer Price Index (CPI) for the southern region as described below.

- Gross State Product (GSP). The measure of income $(Y)$ is the per capita GSP of each state. This is analogous to the GDP measures at the national level. The GSP estimate for each state is obtained from Bureau of Economic Analysis (BEA), U.S. Department of Commerce. GSP per capita is measured in dollars and converted to real terms by using the GDP deflator described below.

- Weather: Heating (H) and Cooling (C) Degrees Days: The degree-days data is meant to be a proxy for climatic conditions. Since the south is generally a warm climate, cooling degrees days are likely to be more important than heating days. However, both variables are initially included in our estimation. This data is obtained from the Historical Climatology Series of the National Oceanic and Atmospheric Administration (NOAA). 
- Population $(\mathrm{N})$ : The census population estimate for each state is measured as the number of persons. Population does not enter our estimation directly as a variable, but it is used as a normalizing variable for income and consumption. The numbers are taken from the U.S. Census Bureau, Department of Commerce.

- Economic Structure (S): The index of the structure of production is calibrated as the proportion of manufacturing output in total GSP. This is our proxy for the structure of the state economy.

- Deflators: The GDP Implicit deflator $(1996=100)$ from the U.S. Bureau of Labor Statistics is the deflator variable for state GSP. Similarly, the CPI $(1982-1984=100)$ for the southern region is the deflator for energy price series.

\section{REFERENCES}

Anderson, T.W. and C. Hsiao, 1982. "Formulating and Estimation of Dynamic Models Using Panel Data," Journal of Econometrics 18, 47-82.

Al-Mutairi, N.H. and M.N. Eltony, 1996. "Price and Income Elasticities of Energy Demand: Some Estimates for Kuwait Using Two Econometric Models," The Journal of Energy and Development 20, 175-85.

Arellano, M., 1989. "A Note on the Anderson-Hsiao Estimator for Panel Data," Economic Letters 31, 337-41.

and S. Bond, 1991. "Some Tests of Specification for Panel Data: Monte Carlo Evidence and Application to Employment Equations," Review of Economic Studies 58, 277-97.

Arsenault, E., J.T. Bernard., C.W. Carr., and E. Genest-Laplante, 1995. “A Total Energy Demand Model of Quebec: Forecasting Properties," Energy Economics 17, 163-71.

Baltagi, B.H. and J.M. Griffin, 1983. "Gasoline Demand in the OECD: Application of Pooling and Testing Procedures," European Economic Review 22, 117-37.

Batalgi, B.H. and C. Kao, 2000. "Nonstationary Panels, Cointegration in Panels and Dynamic Panels: A Survey," Center for Policy Research, Maxwell School of Citizenship and Public Affairs Working Paper No. 16, Syracuse University: Syracuse, NY.

Berck, P. and M. Roberts, 1996. "Natural Resource Prices: Will They Ever Turn Up?” Journal of Environmental Economics and Management 31, 65-78.

Brookes, L.G., 1972. “More on the Output Elasticity of Energy Consumption,” Journal of Industrial Economics, 21, 83-92.

Brown, S.B., 1983. "An Aggregate Petroleum Consumption Model,” Energy Economics 5, 2730 . 
Brown, S. and M. Yucel, 1995. "Energy Prices and State Economic Performance," Economic Review, Federal Reserve Bank of Dallas, Second Quarter, 13-23.

Chen, L. and S.K. Lee, 1997. "Modeling and Forecasting the Demand for Coal in China," Energy Economics 19, 271-87.

Dahl, C., 1994. “A Survey of Energy Demand Elasticities for the Developing World," The Journal of Energy and Development 18, 1-47.

Dismukes, D.E., W.O. Olatubi., and D.V. Mesyanzhinov, 2002. Moving to the Front of the Lines: The Economic Impact of Independent Power Plant Development in Louisiana. Center for Energy Studies, Louisiana State University: Baton Rouge, LA.

Espey, M., 1996. "Explaining the Variation in Elasticity Estimates of Gasoline Demand in the United States: A Meta-Analysis," The Energy Journal 17, 49-61.

Gately, D. and H.G. Huntington, 2001. "The Asymmetric Effects of Changes in Price and Income on Energy and Oil Demand," C.V. Starr Center for Applied Economics Economic Research Reports RR\#: 2001-01, New York University: New York.

Galli, R, 1998. "The Relationship Between Energy Intensity and Income Levels: Forecasting Long-Term Energy Demand in Asian Emerging Countries," The Energy Journal 9, 85-105.

Garcia-Cerrutti, L.M., 2000. "Estimating Elasticities of Residential Energy Demand from Panel County Data Using Dynamic Random Variables Models with Heteroskedastic and Correlated Error Terms," Resource and Energy Economics 22, 355-66.

Halvorsen, R., 1976. "Demand for Electric Energy in the United States," Southern Economic Journal 42, 610-25.

Holtz-Eakin, D. and T.M. Selden, 1995. "Stoking the Fires? $\mathrm{CO}_{2}$ Emissions and Economic Growth," Journal of Public Economics 57, 85-101.

Jones, C.T., 1996. "A Pooled Dynamic Analysis of Inter-Fuel Substitution in Industrial Energy Demand by the G-7 Countries," Energy Economics 28, 815-21.

, 1993. "A Single-Equation Study of U.S. Petroleum Consumption: The Role of Model Specification," Southern Economic Journal 59, 687-700.

Judson, R.A., R. Schmalensee, and T.M. Stoker, 1999. "Economic Development and the Structure of Demand for Commercial Energy," Energy Journal 20, 29-57.

Kesavanathan J., D.L. Swift, and M. Ruth, 1998. "Dematerialization in Five U.S. Metals Sector: Implications for Energy Use and $\mathrm{CO}_{2}$ Emissions," Resources Policy 24, 1-18. 
Kiviet, J.F., 1995. "On Bias, Inconsistency and Efficiency of Some Estimators in Dynamic Panel Data Models," Journal of Econometrics 68, 53-78.

Kouris, G.. 1983. "Fuel Consumption for Road Transport in the United States," Energy Economics 5, 89-99.

Lin, A., E.N. Bostsas, and S.A. Monroe, 1985. "State Gasoline Consumption in the USA," Energy Economics 7, 29-36.

Liu, Ben-Chieh, 1983. "Natural Gas Elasticities: Variation by Region and by Sector in the United States," Energy Economics 5, 195-201.

Medlock III, K.B., and R. Soligo, 2001. "Economic Development and End-Use Energy Demand," The Energy Journal, 22, 77-105.

Moody, C.E., 1996. “A Regional Linear-Logit Fuel Demand Model for Electric Utilities," Energy Economics 18, 295-314.

Murray, M.P., R. Spunn, L. Pulley, and E. Beauvis, 1983. "The Demand for Electricity in Virginia," The Review of Economics and Statistics 60, 585-600.

National Energy Policy Development Group, 2001. National Energy Policy. U.S. Government Printing Office: Washington, D.C.

Nickell, S., 1981. "Biases in Dynamic Models With Fixed Effects," Econometrica, 49, 1417-26.

Prosser, R.D., 1985. “Demand Elasticities in OECD: Dynamic Aspects,” Energy Economics, 912.

Ridder, G. and T. Wansbeek, 1990. "Dynamic Models for Panel Data," in R. van der Ploeg (ed.), Advanced Lectures in Quantitative Economics. Academic Press: New York, 557-82.

Rothman, D.S., J.H. Hong, and T.D. Mount, 1994. "Estimating Consumer Energy Demand Using International Data: Theoretical and Policy Implications," The Energy Journal 15, 6788.

Ryan, D., Y. Wang., and A. Plourde, 1996. "Asymmetric Price Response of Residential Energy Demand in Ontario," Canadian Journal of Economics 29, 317-23.

Schmalensee, R., T.M. Stoker, and R.A. Judson, 1998. "World Carbon Dioxide Emissions: 1950-2050," The Review of Economics and Statistics 80, 15-27.

Sherwood-Call, C., 1996. "The 1980s Divergence in State Per Capita Incomes: What Does it Tell Us?" Federal Reserve Bank of San Francisco, Economic Review 1, 14-25. 
Silk, I.J. and F.L. Joutz, 1997. "Short-and Long-Run Elasticities in U.S. Residential Elasticity Demand: A Cointegration Approach," Energy Economics 19, 493-513.

Southern States Energy Board, 2001. Energy Policy in the South: Integrating Energy, Environment and Economic Development: A Balanced and Comprehensive Approach. Norcross, GA.

Sun, J.W., 2003. "Dematerialization in Finnish Energy Use, 1972-1996," Energy Economics 25, 23-32.

Taylor, L., I. Brown., and S. Boyle, 1990. Lessons from Japan: Separating Economic Growth From Energy Demand. Association for the Conservation of Energy: London, U.K. 